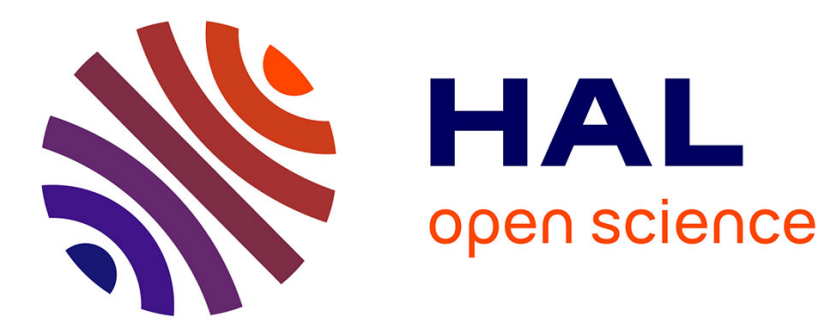

\title{
Individuals' Perception of Which Materials are Most Important to Recycle
}

\author{
Marcus Bjelkemyr, Sasha Shahbazi, Christina Jönsson, Magnus Wiktorsson
}

\section{To cite this version:}

Marcus Bjelkemyr, Sasha Shahbazi, Christina Jönsson, Magnus Wiktorsson. Individuals' Perception of Which Materials are Most Important to Recycle. IFIP International Conference on Advances in Production Management Systems (APMS), Sep 2015, Tokyo, Japan. pp.723-729, 10.1007/978-3-31922756-6_88. hal-01417639

\section{HAL Id: hal-01417639 \\ https://hal.science/hal-01417639}

Submitted on 15 Dec 2016

HAL is a multi-disciplinary open access archive for the deposit and dissemination of scientific research documents, whether they are published or not. The documents may come from teaching and research institutions in France or abroad, or from public or private research centers.
L'archive ouverte pluridisciplinaire HAL, est destinée au dépôt et à la diffusion de documents scientifiques de niveau recherche, publiés ou non, émanant des établissements d'enseignement et de recherche français ou étrangers, des laboratoires publics ou privés. 


\title{
Individuals' perception of which materials are most important to recycle
}

\author{
Marcus Bjelkemyr ${ }^{1}$, Sasha Shahbazi ${ }^{1}$, Christina Jönsson ${ }^{2}$, Magnus Wiktorsson $^{1}$ \\ ${ }^{1}$ School of Innovation, Design and Engineering, Mälardalen University, Eskilstuna, Sweden \\ \{marcus.bjelkemyr, sasha.shahbazi, magnus.wiktorsson\} @mdh.se \\ ${ }^{2}$ Swerea IVF, Stockholm, Sweden \\ christina.jonssoneswerea.se
}

\begin{abstract}
In this study, we have asked respondents to rank ten different waste fractions that are both common in manufacturing industry and easily recognizable. The purpose of the study has been to clarify to what extent individuals are able to identify the waste fractions that are most important to recycle from an environmental perspective. The individuals' perception has then been correlated with a life cycle assessment of the ten materials. In addition, the respondents were also asked to rank the fractions according to cost.

The results show that metals are consistently considered most important to recycle, and plastics are commonly among the top five amongst the ten waste fractions together with glass. The cellulose based fractions, cotton, and compost are commonly rated low. In addition, there is a perceived correlation between the environmental and economic impact.
\end{abstract}

Keywords: Material efficiency, waste management, perceived recycling benefits

\section{Introduction}

Waste management in manufacturing companies is part semi-automatic and part manual. Generally, the direct materials that are machined are automatically transported to the correct waste bin and these are then emptied in larger containers. These materials are often metals, but some other materials may also occur. For these waste fractions the key is to keep them homogeneous and not contaminate them with materials that lower the quality of the fraction, and thereby the value.

Most other waste materials within a manufacturing company are handled manually by the employees. For larger or more valuable waste streams, there are commonly dedicated waste bins that are placed close to where that waste material is generated, and thereby become the easiest place to dispose the waste. However, not all locations where adfa, p. 1, 2011. 
waste is generated can have a dedicated waste bin for each waste fraction because waste bins cost money, take up space, and add complexity to the waste management system. In these cases, the individual factory worker has to both identify the correct waste bin for that material, and estimate the value of transporting the waste to the correct bin, in comparison to throwing it in the closest possible waste bin. To make this choice, the individual has to compare her own additional effort with the perceived benefits for the individual, the company, and the environment.

For the company there is a potential economic gain associated with higher prices for more homogeneous waste fractions; however, this is rarely reflected on the individual level or even group level. Similarly, there is an environmental benefit of increased recycling, but this does not directly affect the individual that is making the choice. Regardless of the direct benefits for the individual, he or she will commonly put in the extra effort if the perceived economic or environmental benefits are high enough. It is therefore important to understand how individuals perceive different waste materials, and it is becoming even more important as consumption, manufacturing, and generated waste volumes increase drastically.

Population growth and increased wealth have caused material demand and energy consumption to increase significantly in the last 100 years. Total global material consumption has increased from 6 billion tons in 1900 to 60 billion tones in 2013, and it is estimated to reach 140 billion tons of key resources per year by 2050 [1]. The total generated waste from manufacturing activities in 2012 accounted for 270 million tons [2] and it is expected to increase by 10-20\% till 2020 in comparison to 2005 [3]. This means that the potential impact of industrial waste management improvements is significant.

The research questions in this study are: (1) do different individuals' perception of environmental impact and economic benefits correlate with each other, and (2) do the individuals' environmental perceptions correlate with the calculated benefits of recycling in comparison to incineration or landfill. The contribution from answering these questions is primarily related an increased understanding of which materials are perceived as more important to recycle than other materials. The results in this study are particularly interesting for the materials that are 
perceived differently by different individuals, and the materials that are perceived either more or less important than they actually are. These discrepancies can then be further analyzed and waste management efforts can be targeted more accurately.

\section{Frame of Reference}

Waste segregation and recycling behavior can be affected in many different ways. According to Maycox [7] the most important variables when changing recycling behavior are to understand why people act the way they do and what their attitudes towards recycling are. Public attitudes towards recycling and municipal solid waste management has been investigated in a multitude of contexts, e.g. [4], [5], [6]. Ajzen [10] clarifies the understanding of recycling behavior and stress that there are both positive and negative drivers; waste segregation and recycling behavior is first influenced by knowledge, infrastructure and proper opportunities, and secondly by aversion of physical recycling issues including time, space and inconvenience. In addition, the moral norm, personality, past experience, demographics, social pressure, convenience, and incentives may also have an impact on recycling and waste management, c.f. $[8,7,9]$.

Homogenous quality of industrial waste is directly connected to the environmental actions and behaviors during operation. Moreover, it is also directly connected to awareness, clear instructions, visualization, and that waste management is sufficiently convenient for the personnel. Among these, intuition and knowledge of operation in waste handling, segregation, and treatment are the key factors [11,12].

Any system implementation and operation becomes easier if the decisions are intuitive, which is highly dependent on involvement of both environmental and operational perspectives [13], particularly when it comes to waste segregation. Even though the environmental coordinators and the engineers play crucial role in waste management, it is still the operators' task to segregate the waste. Hence, the operators' perception concerning environmental benefits of different waste fractions is important to improve waste management and material efficiency. 
This research is based on the idea that individuals will make better waste management choices if they are able to perceive the environmental and economic benefits of recycling correctly. For this to be relevant there must be a significant difference between the benefits of recycling for different materials. In the graph below, $\mathrm{CO}_{2}$ equivalent of the selected fractions have been assessed. The assessment has been gathered from a parallel study [16]; however, the data in the figure below should only be seen as indicative as individual estimates may differ depending on circumstance.

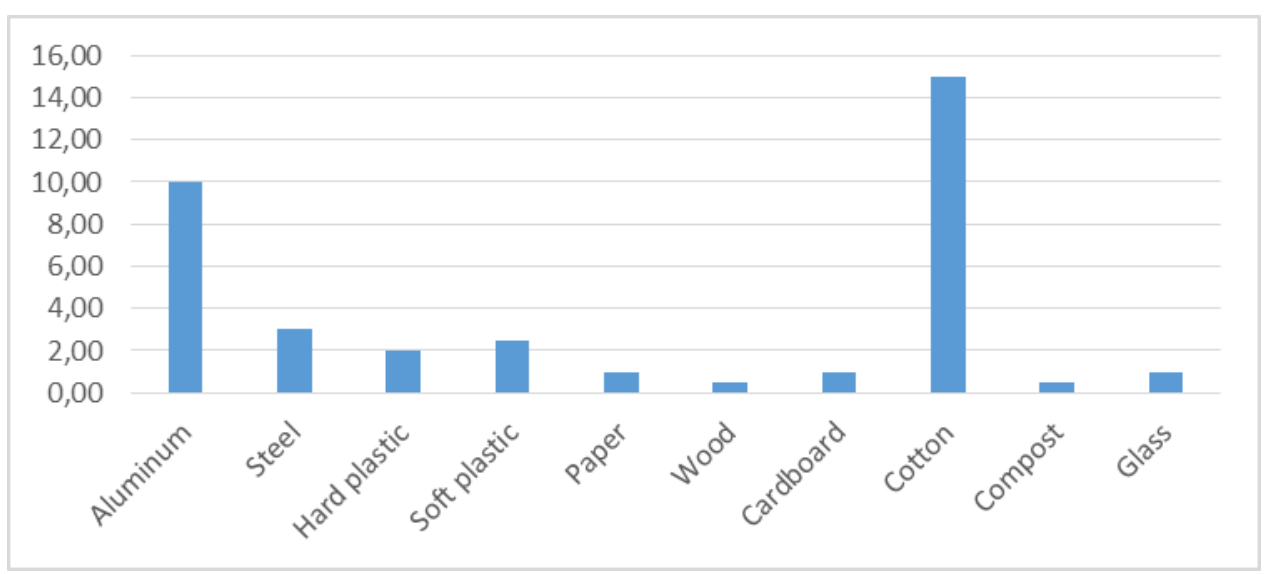

Fig. 1. $-\mathrm{CO}_{2}$ equivalent for the ten researched waste fractions.

\section{Research Methodology}

In the study, 31 respondents were presented with the picture below (figure 2), showing both a photograph and a descriptive term of ten selected waste fractions. These fractions were chosen because they are commonly available in manufacturing industry and/or easily recognizable for individuals without a manufacturing background. Of these ten materials, the respondents were asked to pick out the five materials that are most important to recycle and then rank them, first from an environmental point of view and then from an economic point of view. 


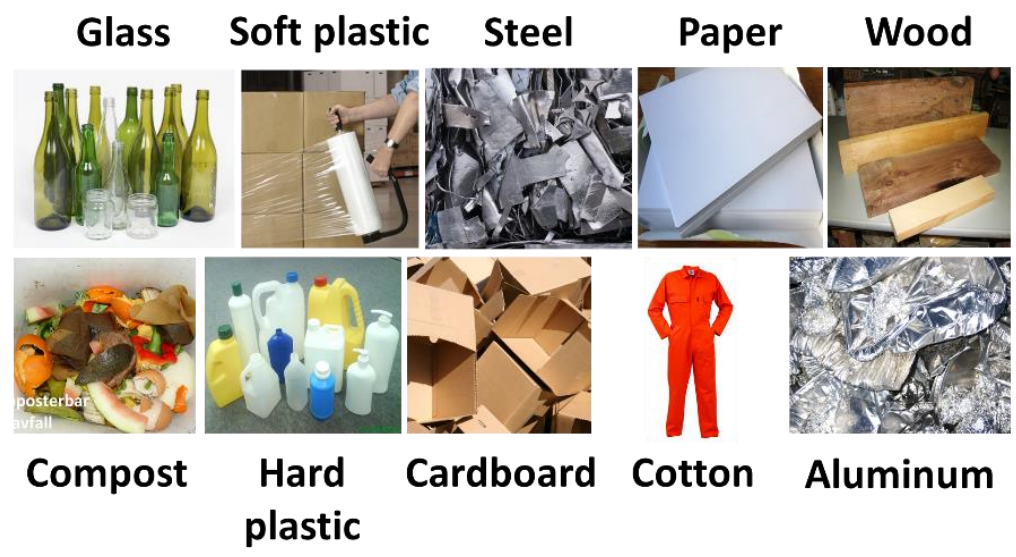

Fig. 2. - Ten waste materials that respondents were asked to rank.

The respondents were all participating in a workshop that was linked to a research program called Closing the Loop, funded by the Swedish Foundation for Strategic Environmental Research Program (Mistra). The reason for choosing this venue was to get answers from individuals that probably have a better understanding of recycling than the average citizen does. The respondents came from industry, academia, institutes, and governmental organizations; their age ranged from 23 to 64 and the average was 43; and the gender distribution was 17 men and 14 women.

In the analysis, the ranked waste materials were given a score of 5 for the most important and 1 for the fifth most important; the materials that were ranked lower were given a zero. The gathered data was analyzed concerning: the distribution of the environmental ranking and the economic ranking. These two were also correlated with each other to see to what extent the respondents considered environment impact and economic benefit to be linked.

\section{$4 \quad$ Empirical Findings and Discussion}

The different respondents' rankings vary greatly, but there are some clear similarities as well (figure 3). The respondents appear to group the different fractions, e.g. metals > glass > plastics > compost, cotton, and cellulose based fractions. This grouping is partly supported by the LCA analysis, but it also results in that some materials are ranked lower than 
they are, e.g. plastics. The variance is partly an effect of how the question was asked, but it also indicates that there is a significant uncertainty when it comes to recycling. This uncertainty reflects that the benefits of recycling specific materials are non-intuitive, and the knowledge level is low.

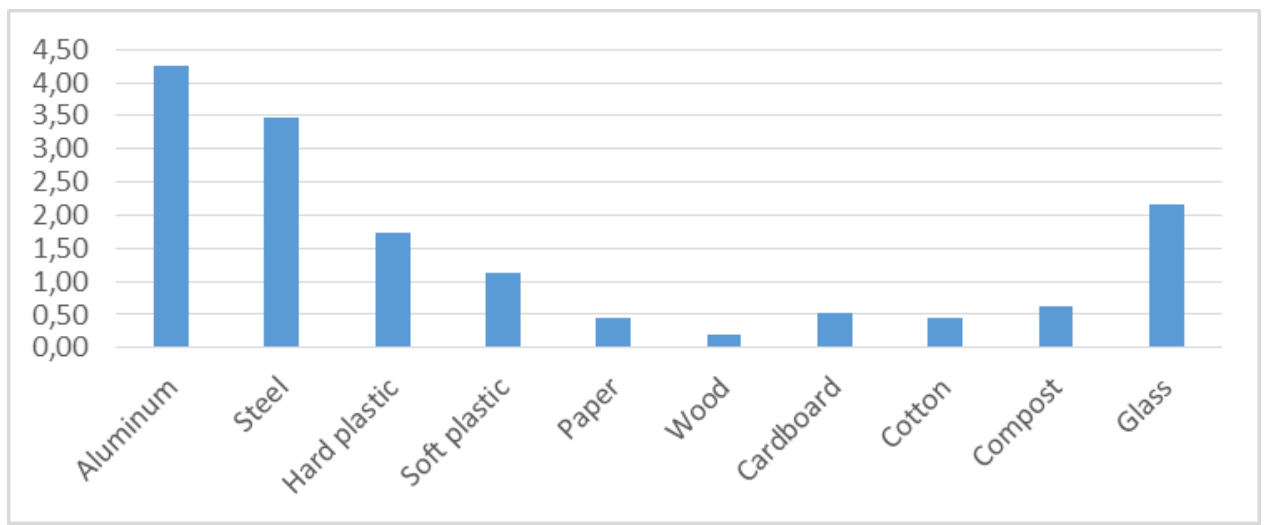

Fig. 3. - Average rank for each material ( $5=$ most important).

Even though the respondents' ranks vary, there are some materials that consistently rank among the five most important materials: aluminum (94\%), steel (97\%), glass (84\%), hard plastics (77\%), and soft plastics (\%) (figure 4).

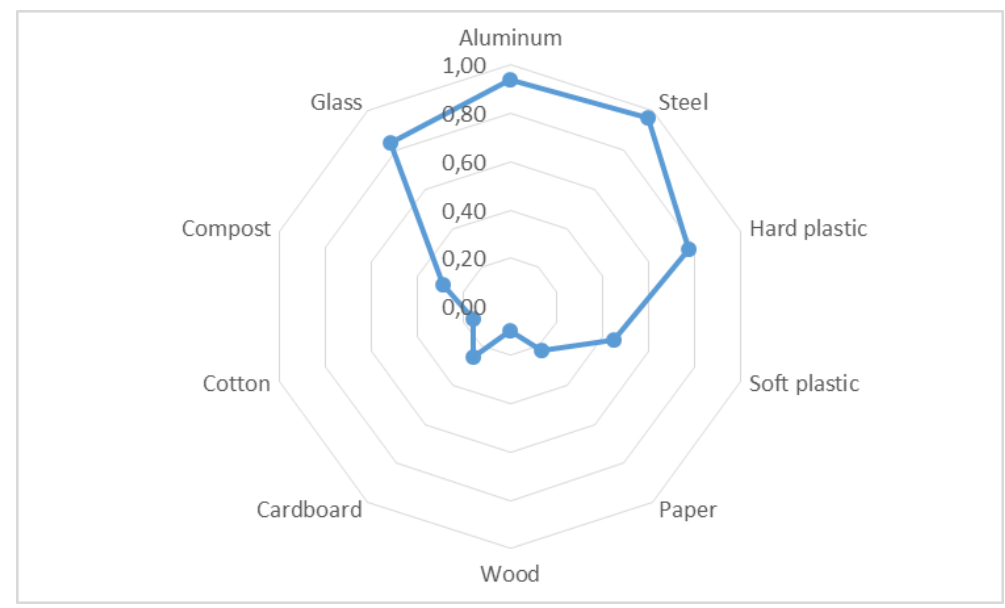

Fig. 4. - Top five rankings of materials (\%). 
For some materials, there is a discrepancy between the environmental impact and the perceived environmental importance to recycle (cf. figures 1,3 , and 4). In the analysis of $\mathrm{CO}_{2}$ equivalents, cotton had the highest value; however, only $16 \%$ of the respondents had included cotton on their top-five list. As a contrast, glass was considered the third most important material by the respondents, but the environmental assessment indicates that has a significantly lower impact than hard and soft plastics.

The respondents' environmental and economic ranks differ, but only slightly (figure 5). This makes it difficult to draw any other conclusions than that the respondents include the economic variable when assessing environmental impact and vice versa.

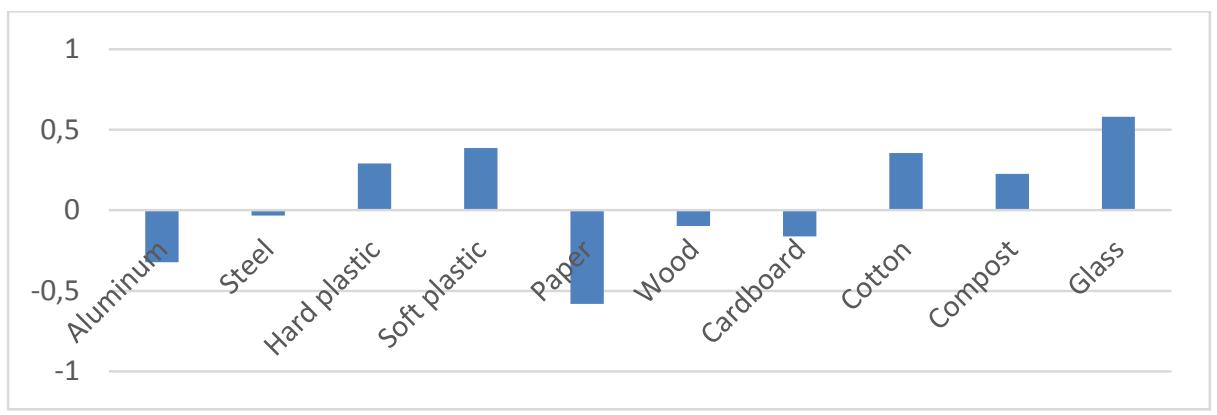

Fig. 5. Difference between environmental and economic rank

\section{Conclusion and Future Study}

The data and the analysis show individuals as a group have a good understanding of which materials are important to recycle. However, plastics are generally underestimated, and the rank of both glass and cotton do not correlate with the LCA analysis. There are several possible reasons for these discrepancies, e.g. direct vs. indirect material, recycling by households, and lack of material understanding.

The study also shows that there is very limited difference between the perceived environmental and economic impact. Further studies are needed to understand the underlying reasons behind the perceived importance of recycling, and how to affect the behavior or individuals. These studies need to look at diverse samples of individuals, e.g. different industries, regions, ages, and backgrounds. 


\section{References}

1. Allwood JM, Ashby MF, Gutowski TG, Worrell E Material efficiency: A white paper. Resources, Conservation and Recycling 55 (3):362-381 (2011)

2. European Commision Waste statistics. http://ec.europa.eu/eurostat/statisticsexplained/index.php/Waste_statistics (accessed 2015)

3. Frostell $B$ The Future, Rest Products and Waste; How Will Waste Management Look Like in 2020? Ragn-Sells AB, KTH, School of Industrial Engineering and Management (ITM), Industrial Ecology.(2006)

4. Leaman J, Harvey $P$, Durkacz $S$ Public attitudes towards recycling and waste management Ipsos MORI(2006)

5. Barr S Factors Influencing Environmental Attitudes and Behaviors A UK Case Study of Household Waste Management. Environment and behavior Vol. 39, No. 4:pp. 435-473 (2007)

6. Purcell M, Magette W Attitudes and behaviour towards waste management in the Dublin, Ireland region. Waste Management Vol. 30, No. 30 (10):pp. 1997-2006 (2010)

7. Maycox A The village initiative project: Achieving household waste minimisation in the rural locale. Chartered Institution of Wastes Management Journal Vol. 4, No. 3 (3):pp. 10-17 (2003)

8. Barr S, Gilg AW, Ford NJ A conceptual framework for understanding and analysing attitudes towards household-waste management. Environment and Planning $A$ Vol. 33, No. 11:pp. 2025-2048 (2001)

9. Tonglet M, Phillips PS, Bates MP Determining the drivers for householder proenvironmental behaviour: waste minimisation compared to recycling. Resources, Conservation and Recycling Vol. 42, No. 1 (1):pp. 27-48 (2004)

10. Ajzen I The theory of planned behavior. Organizational Behavior and Human Decision Processes Vol. 50, No. 2:pp. 179-211 (1991)

11. Oskamp S, Harrington MJ, Edwards TC, Sherwood DL, Okuda SM, Swanson DC Factors influencing household recycling behavior. Environment and behavior Vol. 23, No.4 (4):pp. 494-519 (1991)

12. Barr S, Gilg AW A conceptual framework for understanding and analyzing attitudes towards environmental behaviour. Geografiska Annaler: Series B, Human Geography Vol. 89, No. 4:pp. 361-379 (2007)

13. Zhang HC, Kuo TC, Lu H, Huang SH Environmentally conscious design and manufacturing: A state-of-the-art survey. Journal of Manufacturing Systems Vol. 16, No. 5 (5):pp. 352-371 (1997)

14. Kurdve M, Shahbazi S, Wendin M, Bengtsson C, Wiktorsson M Waste flow mapping to improve sustainability of waste management: a case study approach. Journal of Cleaner Production(2014)

15. Norgate $T$, Rankin $W$ The role of metals in sustainable development. Green Processing:49-55 (2002)

Jönsson C, Wilson K LCA Memiman - Material efficiency in manufacturing, report (2015) 